\title{
Current impact and future consequences of the pandemic on children's and adolescents' health
}

\author{
Nicolás Cacchiarelli San Román, M.D. .,b,c, Alfredo Eymann, M.D..$^{a, b, c}$ and \\ Jorge R. Ferraris, M.D. ${ }^{c, d}$
}

\begin{abstract}
There is plenty bibliography about the impact of the coronavirus disease 2019 (COVID-19) pandemic on the mental and social health of children, adolescents, and youth.

A very high percentage of this population developed emotional symptoms and their levels of anxiety, depression, and suicidal ideation increased considerably. The adults who were responsible for generating a support network were impacted and suffered emotional symptoms and job and economic uncertainty. In many children, without a supportive context, exposure to adverse experiences increased, so the pandemic may be considered an adverse experience itself. The future effect of such unfavorable experience on childhood and how family and social support may help to reduce stress through the development of resilience were reviewed.

As citizens and health care providers, our responsibility is to reflect, discuss, and develop strategies to mitigate such damage that may have severe consequences on the mental and physical health of children and adults.

Key words: COVID-19, adverse childhood experiences, mental health, secondary prevention, child health.
\end{abstract}

http: / / dx.doi.org/10.5546/ aap.2021.eng.e594

To cite: Cacchiarelli San Román N, Eymann A, Ferraris JR. Current impact and future consequences of the pandemic on children's and adolescents' health. Arch Argent Pediatr 2021;119(6):e594-e599.

\section{INTRODUCTION}

On March 11 ${ }^{\text {th }}, 2020$, the World Health Organization (WHO) declared that the new coronavirus disease 2019 (COVID-19) had become a pandemic. ${ }^{1}$

The WHO defined health in 1948 as "a state of complete physical, mental, and social well-being and not merely the absence of disease". ${ }^{2}$ In 2011, Huber et al. questioned such definition and proposed the following: "the ability to adapt and self-manage in the face of social, physical, and emotional challenges". ${ }^{3}$

As observed, both definitions include the concept of health not only in its physical aspect, but also its emotional and social facets.

There is broad evidence of the disruptive impact of toxic stress on childhood, known as the body's response to severe and long-lasting stress, without sufficient support from an adult. Environmental effects may leave a long-lasting imprint on genetics. Some mechanisms have established a relationship between early adverse experiences and subsequent deficiencies in learning, behavior, and physical and mental well-being. In addition, some frequent severe diseases in adults are secondary to a poor adaptation to stress starting early in life. ${ }^{4}$

The body undergoes an adaptation process to maintain or restore its physiological balance in the presence of changing circumstances, such as physical, psychosocial, and environmental stressors, known as allostasis. As exposure to stressful situations increases, the allostatic load also increases and, with it, the risk for disease. ${ }^{5,6}$ 
In many children, the COVID-19 pandemic increased the exposure to adverse experiences and may be considered one itself, which, in addition to having an impact on current health, entails a bigger risk for adult diseases. ${ }^{7}$ Promoting resilience mechanisms in pediatric patients to reduce the allostatic load is an opportunity to improve their future health and reduce the negative impact of stress. ${ }^{8}$

The objective of this study was to review and describe selected studies related to the impact of the COVID-19 pandemic on mental and social health of children, adolescents, and youth, and the long-term impact of adverse childhood experiences (ACEs) to alert the society of its consequences.

\section{EMOTIONAL IMPACT ON CHILDREN, ADOLESCENTS, AND YOUTH IN ARGENTINA}

In Argentina, the first imported COVID-19 case was confirmed on March $3^{\text {rd }}, 2020 .{ }^{9}$

The measures established by the Executive Branch, in agreement with the WHO recommendations to control the pandemic, included a preventive and mandatory social isolation policy between March 20 th 2020 and November $30^{\text {th }}, 2020$ and, from that date, a preventive and mandatory social distancing policy. ${ }^{10,11}$

By the end of May 2021, approximately 3.7 million people had suffered COVID-19, with a mean age of 40 years and a similar men to women ratio. A total of 76693 had died and $70 \%$ of them were older than 60 years. The risk for death due to COVID-19 among individuals younger than 19 years was $0.2 \% .^{12}$

A study that analyzed the emotional impact of the COVID-19 pandemic in 1410 adults in the province of Córdoba, Argentina, described that the most common negative feelings were fear, uncertainty, distress, and anxiety, whereas perceived positive consequences included solidarity, health, awareness, and empathy.$^{13}$ Another study conducted in Argentina analyzed perceptions and feelings regarding the COVID-19 lockdown using anonymous surveys completed by 4762 children and adolescents from across the country. ${ }^{14}$ According to that study, $71 \%$ described sadness; $91 \%$ said that they missed other people; $77 \%$ expressed anger; and 80\%, concern. Eighty percent underscored the need to reconnect and restore the bond with their family, friends, and ties, and 65\% emphasized the need to do outdoor activities. A study conducted in the city of Bariloche assessed the psychological impact of social isolation on children through their parents' perception. The results showed that $96 \%$ of parents referred emotional changes and the most frequent ones were boredom $(77 \%)$, irritability $(59 \%)$, reluctance $(57 \%)$, and anger $(54 \%){ }^{15}$

\section{IMPACT OF THE PANDEMIC ON THE MENTAL HEALTH OF THE GENERAL POPULATION}

To understand the relevance of the situation, it is important to describe its impact on the general population, which includes many adults who are caregivers of children. Caregivers with psychological problems have a lower ability to offer support to children and adolescents; therefore, their ability to alleviate their negative feelings about the pandemic is also lower.

A study conducted in 190 cities of China assessed the psychological impact of the pandemic on 1738 subjects aged 12-59 years in 2 moments: January 2020 and March 2020. The results showed that $54 \%$ of subjects had a moderate to severe psychological impact, with stress levels of $8 \%$, anxiety levels of $29 \%$, and depression levels of $16 \%$, which remained constant over time. These data alert about the continuation of such effects over time. In addition, $30 \%$ had somatic symptoms such as headache, cough, dizziness, rhinitis, odynophagia, and chills. ${ }^{16}$

Another study that measured the psychological effects of the pandemic focused on health care staff and showed similar results: $50 \%$ had depression (severe in $10 \%$ ); $55 \%$, anxiety (severe in 15\%); $42 \%$, stress (severe in 5\%); and $50 \%$, post-traumatic stress (severe in $7 \%$ ). Also, $34 \%$ of subjects had more than 4 somatic symptoms, including insomnia, tiredness, anxiety, odynophagia, and headache, similar to what has been described by people with COVID-19. ${ }^{17}$

Such psychological impact adds to the changes in family living habits and the concerns about the financial situation. A study conducted in the United States of America (USA) showed that 80\% of adults suffered job insecurity and $32 \%$ had financial uncertainty about their future more than 1 year after the onset of the pandemic. This study points out that both situations caused anxiety and depression in $46 \%$ of surveyed children. ${ }^{17}$ Such job 
and financial uncertainty also had a major impact on Argentine households. According to data by the National Statistics and Censuses Institute of Argentina, in December 2020 in Greater Buenos Aires, $49 \%$ of households experienced a reduction in their income and in 40\%, 1 family member suffered a problem with their employment, either layoff or furlough. Households with a lower level of education were affected the most. In $34 \%$ of households, the consumption of a basic food reduced. In $66 \%$ of households, the time parents spent helping their children with school assignments increased. Also, $48 \%$ received assistance from the government; $11 \%$ requested a loan; and $28 \%$ interrupted utility payments. ${ }^{18,19}$

\section{IMPACT OF THE PANDEMIC ON THE MENTAL HEALTH OF CHILDREN, ADOLESCENTS, AND YOUTH}

In a review of 51 studies conducted in Asian countries about the psychological effect of the pandemic on children, adolescents, and youth that assessed a total of 11599 subjects, it was observed that $18 \%$ of the group aged 6-12 years had anxiety and $17 \%$ had depression; in the group aged $12-18$ years, $36 \%$ had anxiety and $41 \%$, depression. Clearly, the adolescent population was affected the most, especially girls. ${ }^{20}$

Another study compared the effects of the pandemic on pediatric populations from Spain and Italy. Emotional symptoms were observed in $85.7 \%$; the most common ones were difficulty focusing (52\%), irritability (39\%), restlessness $(39 \%)$, agitation $(38 \%)$, loneliness $(32 \%)$, anxiety $(30 \%)$, and concern $(30 \%) .{ }^{21}$ When the symptoms described in that study are analyzed based on the diagnostic criteria of anxiety and depression, it may be inferred that $27 \%$ had anxiety and $38 \%$, depression. The effects were greater among Spanish than Italian subjects. This may be because schools opened again sooner and the lockdown period was shorter in Italy than in Spain. Evidently, the impact of the pandemic on pediatric mental health was similar in both the East and the West.

Young adults were also affected. In a study conducted in 7134 students in China, ${ }^{22} 23 \%$ showed anxiety symptoms, which were higher among youth residing in rural areas and who did not have a stable income, who did not live with their parents or whose family or friends had had COVID-19. In addition, financial concerns, delay in academic years, and loss of social support were described as stressors. Another study conducted in the USA assessed 2031 university students; $48 \%$ had depression; $38 \%$, anxiety; and $18 \%$, suicidal ideation. $^{23}$

The latter was also observed in studies carried out in Europe, where 9\% of university students had suicidal ideation. ${ }^{24}$

These findings are even more alarming when compared to the levels of anxiety, depression, and suicidal ideation in different parts of the world before the pandemic. Depending on the location, anxiety in this age group ranged between 3\% in the USA and 6\% in China; depression ranged between $2 \%$ and $6 \%$ in the West and $15 \%$ in China. However, suicidal ideation was present in $1.2 \%$ of the general population..$^{25-28}$

\section{FUTURE IMPACT OF ADVERSE CHILDHOOD EXPERIENCES}

The effects of the COVID-19 pandemic on the mental health of the pediatric population (anxiety, depression, post-traumatic stress, and suicidal ideation) may have long-term consequences. ${ }^{7}$

The bibliography broadly supports the impact of ACEs on health. These events include different forms of abuse, physical and emotional neglect, family instability, learning deficit, financial instability, natural disasters, among others..$^{29,30}$

In the original study of ACEs, investigators concluded that they had a deep impact on healthrelated outcomes later in life. In the case of repeated ACEs, programming may occur in 3 areas at an individual level: ${ }^{31-33}$

1. At a central level, it reduces emotional regulation ability and increases threat response. The size of the hippocampus, tonsil, and prefrontal cortex is reduced, and the consequences include alterations in corticolimbic and corticostriatal connectivity.

2. At an immuno-endocrine level, inflammatory changes occur with an increase in proinflammatory cytokines and a reduction in anti-inflammatory cytokines, an alteration in hormone medium with hypothalamicpituitary-adrenal axis activation, onset of hypercortisolism, an increase in epinephrine, norepinephrine, and acetylcholine, and a reduction in oxytocin. Proinflammatory cytokines (IL-6, TNF-alpha, and IFN-gamma) are associated with depression and are also increased in patients with COVID-19, which 
may account for their psychiatric symptoms.

3. Lastly, there are epigenetic changes such as hypermethylation of glucocorticoid receptor, a reduction in cortisol response and, therefore, a hyper-activation of the hypothalamic-pituitary-adrenal axis. The chronic elevation of glucocorticoids will lead to hippocampus, tonsil, and prefrontal cortex remodeling, which would account for neurodevelopmental alterations in these children and their learning ability and skills in the brain.

The early Homo sapiens was programmed: they woke up every morning, needed to remain alert, and could not think of anything else than getting food for the day, being careful not to get wounded, and healing their wounds rapidly. They only programmed their day to day survival and died soon. Currently, these changes manifest later in life.

An individual who has suffered repeated adverse experiences during their childhood, without adequate resilience mechanisms, becomes more sensitive to psychological dysregulation, which causes depression, and physiological dysregulation, which is associated with the following problems during adulthood: ${ }^{30}$

- Health risk behaviors: alcohol, tobacco, and drug abuse, higher risk for unintended pregnancy, sexually transmitted infections, and obesity.

- Chronic diseases: cardiovascular disease, stroke, liver disease, lung cancer, chronic obstructive pulmonary disease, rheumatoid arthritis, frequent headache, primary insomnia, metabolic syndrome, and changes in immune function.

- Mental health: behavioral alterations, psychosomatic disorders, hallucinations, anxiety, obsessive compulsive disorder. In addition, having 4 or more ACEs increases the risk for depression by 4.5 times and the risk for suicide attempt by 12.5-15.5 times in adulthood.

Considering the impact of sustained stress, mechanisms emerge that facilitate resilience, act as buffers, and may help to reduce the future impact of ACEs. Among such secondary prevention resources, the most studied ones include psychological assistance programs, parent-child bonding therapy, social support, and development of stress management skills..$^{30,34}$

\section{FINAL REMARKS}

The changes imposed by the pandemic in relation to virtual education, virtual access to the health care system, how people communicate, and so many new modalities will probably become part of our practice once this disaster is over. However, the damage the pandemic has caused and continues to cause in terms of social, educational, financial, developmental, and human losses is undeniable and has affected the mental and social health of children, adolescents, and youth. Over the course of the pandemic, many children will remember the affection and fondness of their parents, but many others will remember being punished and neglected.

Although a limitation of this review is that many analyzed studies corresponded to surveys and this does not constitute a systematic review, all agree that it is important to point out the major impact observed on mental health during the pandemic, to the extent of considering it an adverse childhood experience. Therefore, it is necessary to remain alert and thus prevent the future consequences of such impact on population health.

As shown in this review, caregivers, families, teachers, and society in general are not exempt and may therefore have a lower ability to provide support and generate strategies to reduce the negative impact of such chronic stress on children and adolescents.

Therefore, it is the responsibility of health care providers, as such and as citizens, to reflect, discuss, and establish secondary prevention strategies to mitigate such damage and tertiary prevention strategies to manage any damage that has already occurred.

To this end, it is necessary for facilities, families, health care and education teams and any childhood-related organization to understand the effects of trauma and toxic stress, as well as the importance of developing positive and trusted relationships to face these events.

As Carlos Gianantonio used to say: “A pediatrician looks after children, human beings in whom small experiences at such a young age have a huge effect on their future".

\section{REFERENCES}

1. Organización Mundial de la Salud. Cronología de la respuesta de la OMS a la COVID-19. 2021. [Accessed on: 
January $\left.29^{\text {th }}, 2021\right]$. Available at: https:/ / www.who.int / es/news/item/29-06-2020-covidtimeline

2. World Health Organization. Preamble to the Constitution of the World Health Organization as adopted by the International Health Conference, New York, 19-22 June, 1946. Geneva: WHO; 1946.

3. Huber M, Knottnerus JA, Green L, van der Horst H, et al. How should we define health? BMJ. 2011; 343:d4163.

4. Shonkoff JP, Garner AS; Committee on Psychosocial Aspects of Child and Family Health; Committee on Early Childhood, Adoption, and Dependent Care; Section on Developmental and Behavioral Pediatrics. The lifelong effects of early childhood adversity and toxic stress. Pediatrics. 2012; 129(1):e232-46.

5. Lemos M. La teoría de la alostasis como mecanismo explicativo entre los apegos inseguros y la vulnerabilidad a enfermedades crónicas. Anal Psicol. 2015; 31(2):452-61.

6. Danese A, McEwen BS. Adverse childhood experiences, allostasis, allostatic load, and age-related disease. Physiol Behav. 2012; 106(1):29-39.

7. Bryant DJ, Oo M, Damian AJ. The rise of adverse childhood experiences during the COVID-19 pandemic. Psychol Trauma. 2020; 12(S1):S193-4.

8. Traub F, Boynton-Jarrett R. Modifiable Resilience Factors to Childhood Adversity for Clinical Pediatric Practice. Pediatrics. 2017; 139(5):e20162569.

9. Argentina. Ministerio de Salud. Salud confirma el primer caso decoronaviursenel país[Internet]. Buenos Aires:MISAL;2020 mar 3. [Accessed on: June 16 $\left.{ }^{\text {th }}, 2020\right]$. Available at: https:/ / www.argentina.gob.ar/noticias/salud-confirma-el-primercaso-de-coronavirus-en-el-pais

10. Decreto $297 / 20$. Aislamiento social preventivoy obligatorio. Boletín Oficial de la República Argentina. Buenos Aires, 19 de marzo de 2020. [Accessed on: June $16^{\text {th }}, 2021$ ]. Available at: https: / / www.boletinoficial.gob.ar/detalleAviso / primera/227042/20200320.

11. Decreto $956 / 2020$. Aislamiento social preventivo y obligatorio y distanciamiento social, preventivo y obligatorio. Boletín Oficial de la República Argentina. Buenos Aires, 29 de noviembre de 2020. [Accessed on: November $\left.29^{\text {th }}, 2020\right]$. Available at: https: / / www.boletinoficial.gob. ar / detalleAviso/ primera/237844/20201130

12. Argentina. MinisteriodeSalud.Informaciónepidemiológica: mayo de 2021. Buenos Aires, mayo 2021. [Accessed on: June $\left.16^{\text {th }}, 2021\right]$. Available at: https://www.argentina.gob.ar/ coronavirus / informes-diarios / sala-de-situacion / mayo2021.

13. Johnson MC, Saletti-Cuesta L, Tumas N. Emociones, preocupaciones y reflexiones frente a la pandemia del COVID-19 en Argentina. Cien Saude Colet. 2020; 25(Suppl 1):2447-56.

14. Cabana JL, Pedra CR, Ciruzzi MS, Garategaray MG, et al. Percepciones y sentimientos de niños argentinos frente a la cuarentena COVID-19. Arch Argent Pediatr. 2021;119(4):S10722.

15. Schnaiderman D, Bailac M, Borak L, Comar H, et al. Impacto psicológico del aislamiento por COVID-19 en jóvenes de San Carlos de Bariloche, Argentina: la mirada de los padres. Arch Argent Pediatr. 2021; 119(3):170-6.
16. Wang C, Pan R, Wan X, Tan Y, et al. A longitudinal study on the mental health of general population during the COVID-19 epidemic in China. Brain Behav Immun. 2020; 87:40-8.

17. Chew NWS, Lee GKH, Tan BYQ, Jing $M$, et al. A multinational, multicentre study on the psychological outcomes and associated physical symptoms amongst healthcare workers during COVID-19 outbreak. Brain Behav Immun. 2020; 88:559-65.

18. Instituto Nacional de Estadística y Censos-INDEC. Estudio sobre el impacto de la COVID-19 en los hogares del Gran Buenos Aires: agosto-octubre 2020: primer informe de resultados. Buenos Aires: INDEC; 2020 [Accessed on: June $16^{\text {th }}$, 2021]. Available at: https:/ / www.indec.gob.ar/ftp/ cuadros/sociedad/EICOVID_primer_informe.pdf

19. Instituto Nacional de Estadística y Censos-INDEC. Estudio sobre el impacto de la COVID-19 en los hogares del Gran Buenos Aires: agosto-octubre 2020: segundo informe de resultados. Buenos Aires: INDEC; 2020 [Accessed on: June $16^{\text {th }}$, 2021]. Available at: https:/ / www.indec.gob.ar/ftp/ cuadros/sociedad/EICOVID_segundo_informe.pdf

20. de Miranda DM, Athanasio BS, Oliveira ACS, Simoes-ESilva AC. How is COVID-19 pandemic impacting mental health of children and adolescents? Int JDisaster Risk Reduct. 2020; 51:101845.

21. Orgilés M, Morales A, Delvecchio E, Mazzeschi C, Espada JP. Immediate Psychological Effects of the COVID-19 Quarantine in Youth From Italy and Spain. Front Psychol. 2020; 11:579038.

22. Cao W, Fang Z, Hou G, Han M, et al. The psychological impact of the COVID-19 epidemic on college students in China. Psychiatry Res. 2020; 287:112934.

23. Wang X, Hegde S, Son C, Keller B, et al. Investigating Mental Health of USCollegeStudents During the COVID-19 Pandemic: Cross-Sectional Survey Study. J Med Internet Res. 2020; 22(9):e22817.

24. Kaparounaki CK, Patsali ME, Mousa DV, Papadopoulou EVK, et al. University students' mental health amidst the COVID-19 quarantine in Greece. Psychiatry Res. 2020; 290:113111.

25. Phillips MR, Liu H, Zhang Y. Suicide and social change in China. Cult Med Psychiatry. 1999; 23(1):25-50.

26. Mojtabai R, Olfson M, Han B. National Trends in the Prevalence and Treatment of Depression in Adolescents and Young Adults. Pediatrics. 2016; 138(6):e20161878.

27. Cui Y, Li F, Leckman JF, Guo L, et al. The prevalence of behavioral and emotional problems among Chinese school children and adolescents aged 6-16: a national survey. Eur Child Adolesc Psychiatry. 2021; 30(2):233-41.

28. World Health Organization. Adolescent mental health. Geneva: WHO; 2020 sept 28. [Accessed on: June 16 $6^{\text {th }}, 2021$ ]. Available at: https://www.who.int/news-room/factsheets / detail/adolescent-mental-health

29. Finkelhor D. Trends in Adverse Childhood Experiences (ACEs) in the United States. Child Abuse Negl. 2020; 108:104641.

30. Oral R, Ramirez M, Coohey C, Nakada S, et al. Adverse childhood experiences and trauma informed care: the future of health care. Pediatr Res. 2016; 79(1-2):227-33. 
31. Fagundes CP, Glaser R, Kiecolt-Glaser JK. Stressful early life experiences and immune dysregulation across the lifespan. Brain Behav Immun. 2013; 27(1):8-12.

32. Miller GE, Chen E, Parker KJ. Psychological stress in childhood and susceptibility to the chronic diseases of aging: moving toward a model of behavioral and biological mechanisms. Psychol Bull. 2011; 137(6):959-97.
33. Berens AE, Jensen SKG, Nelson CA $3^{\text {rd }}$. Biological embedding of childhood adversity: from physiological mechanisms to clinical implications. BMC Med. 2017; 15(1):135.

34. Bethell CD, Newacheck P, Hawes E, Halfon N. Adverse childhood experiences: assessing the impact on health and school engagement and the mitigating role of resilience. Health Aff (Millwood). 2014; 33(12):2106-15. 